\title{
Plate-strengthened deep reinforced concrete coupling beams
}

$1 \quad$ R. K. L. Su PhD, CEng, MIStructE, MHKIE, RPE (HK), IRSE (PRC) Department of Civil Engineering, The University of Hong Kong
2 B. Cheng MEng

Department of Civil Engineering, The University of Hong Kong

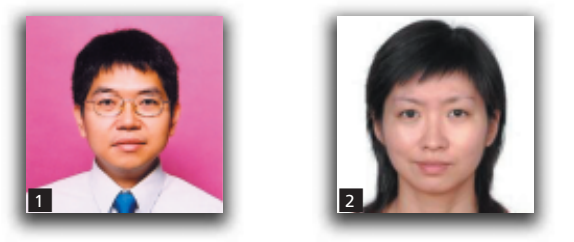

Many old reinforced concrete buildings in developed countries need to be strengthened due to the aging of construction materials, changes in functional use or new design loading requirements. In the present study, a series of experiments were conducted attempting to retrofit deep reinforced concrete coupling beams using a bolted steel plate. In addition to the control specimen, the other specimens were bolted with a steel plate on the side face to improve the shear strength and inelastic behaviour. A mechanical device was added to two specimens to restrain plate buckling. The study revealed that adding an external plate is an effective way to improve the shear capacity, energy dissipation and rotation deformability of deep reinforced concrete coupling beams. Moreover, the plate buckling-restrained specimen with a sufficient number of bolts in the anchor regions had a more stable response and better inelastic performance under reversed cyclic loads. These findings can help designers to a better understanding of this type of composite coupling beam.

\section{Notation}

E elastic modulus

$f_{\mathrm{c}} \quad$ average cylinder compressive strength

$f_{\text {cu }} \quad$ average cube compressive strength

$f_{\mathrm{y}} \quad$ tensile yield strength

$K_{0} \quad$ secant stiffness

$l$ clear span

$V_{\max }$ maximum measured shear

$V_{\text {peak1 }}$ peak loads of each specimen at a nominal ductility level

$V_{\text {peak2 }}$ peak loads of each specimen in repeated loading cycles

$V_{\mathrm{u}}^{*} \quad$ theoretical ultimate shear capacity

$W_{\mathrm{d}} \quad$ energy dissipated

$\Delta \quad$ differential displacement between the two beam ends in the loading direction

$\theta \quad$ beam rotation

$\theta_{\mathrm{y}} \quad$ actual yield rotation

$\theta_{\mathrm{yn}}$ nominal yield rotation

$\mu_{\mathrm{n}} \quad$ nominal ductility factor

\section{Introduction}

Many old reinforced concrete (RC) buildings in developed countries and cities need to be strengthened due to the introduction of new design loading requirements, rapid deterioration of reinforced concrete and, in some cases, poor original concrete quality. It is often more economical to retrofit affected structural components than to demolish entire buildings.

Coupled beams in coupled shear walls are very important structural components that provide the necessary lateral strength, stiffness and deformability for the whole building to resist extreme environmental loads, including wind and earthquake. To ensure the desired behaviour of coupled shear wall systems, coupling beams should be sufficiently strong to resist wind load, and have good energy dissipation ability and a low strength degradation rate for seismic-resistant applications. Paulay (1971a) studied the behaviour of conventional RC coupling beams in shear wall structures. He pointed out that the behaviour of coupling beams was different from that of ordinary beams, especially when the span-to-depth ratio was low because shear deformations may become very significant. Many of the coupling beams designed to be conventional flexural members will inevitably fail from diagonal tension when the shear reinforcement is insufficient, and when the shear reinforcement is sufficient, sudden sliding shear failure can occur at the beam-wall joints. Many studies (Harries et al., 1993; Kwan and Zhao, 2002a; Lam et al., 2005; Paulay and Binney, 1974; Teng et al., 1999) have been conducted aiming to improve the strength and energy dissipation of conventional $\mathrm{RC}$ coupling beams. 
To increase the shear capacity of existing RC floor beams, there are basically two widely used methods. The first method is to adhesively bond advanced composites, such as glass-fibre reinforced plastic and carbon-fibre reinforced plastic, or steel plate onto the side faces of the members. However, many studies have indicated that the composite or the steel plate is prone to peeling and debonding under cyclic loading (Teng et al., 2002). The second method is to bolt steel plates to the side faces of the members. Bolting can ensure long-term durability and reliability, and can avoid the problem of peeling and the need for surface preparation on site. One of the drawbacks of bolting construction is that it may weaken the concrete components due to drilling of bolt holes through the concrete.

Compared with the research about strengthening of RC floor beams, only a few studies (Harries et al., 1996; Su and Zhu, 2005) are applicable to strengthening existing RC coupling beams. Harries studied different ways to fix a thin steel plate to one side of medium-length coupling beams and suggested using anchor bolts together with epoxy bond to attach the steel plate across the span from one beam-wall joint to the other. Su and Zhu attempted through experiments to strengthen the shear capacity of medium-length RC coupling beams by bolting steel plates only at beam-wall joints without adhesive bonding between the concrete and the steel plates, and conducted numerical studies to demonstrate the effectiveness of their retrofitting method. In all their experiments, minor buckling of the steel plate was observed and the influence of local buckling on the behaviour of composite coupling beams was not investigated. Moreover, all available studies (Harries et al., 1996; Su and Zhu, 2005) have focused only on the shear strengthening of mediumlength coupling beams with span-to-depth ratios $\geqslant 2$. The behaviour of deep coupling beams is very different from that of medium-length coupling beams (Paulay, 1971a). Deep concrete coupling beams reinforced with conventional shear stirrups tend to fail in a brittle fashion under reversed cyclic loading, which is not desirable for seismic resistant design (Paulay, 1971b). In order to improve the performance of existing deep RC coupling beams under wind or earthquake actions, the present study aimed to develop a new retrofitting method for this type of beam.

In the present study, deep RC coupling beams with a small spanto-depth ratio of 1.11 were retrofitted and tested. An external steel plate together with anchor bolts fixing at the beam-wall joints was adopted. Anchor bolts were not placed along the span of the beam to avoid bolt holes damaging the critical concrete struts in the span and clashing with the main reinforcement and shear links of the RC beams. As large rotations of the beam-wall joints and high axial deformation in the deep coupling beams could lead to local buckling of steel plates, a buckling restraining device was added. The advantage of using buckling restraining device instead of adding stiffeners to the steel plates for controlling plate buckling is that the stiffness of the coupling beams would not be increased. It is important as the increase of beam stiffness would stiffen up the lateral load-resisting system of the structure and cause the structure to attract more lateral seismic loads which might lead to the brittle failure of the coupled shear walls under strong seismic loads. The present study will demonstrate that the proposed method can result in better energy dissipation ability, lower strength degradation rate and more ductile performance for the strengthened RC coupling beams. These desirable features make this method suitable for seismic retrofitting of deep RC coupling beams in high seismicity areas.

\section{Experimental programme}

\subsection{Test set-up}

Four reversed cyclic loading tests were conducted to investigate the structural performance of deep concrete coupling beams strengthened with external steel plates. The load frame (Kwan and Zhao, 2002b) shown in Figure 1 was employed in the tests. To facilitate the loading application, specimens were rotated $90^{\circ}$ from the actual position. The bottom end of the specimen was attached to a horizontal steel beam fixed on the strong floor, and

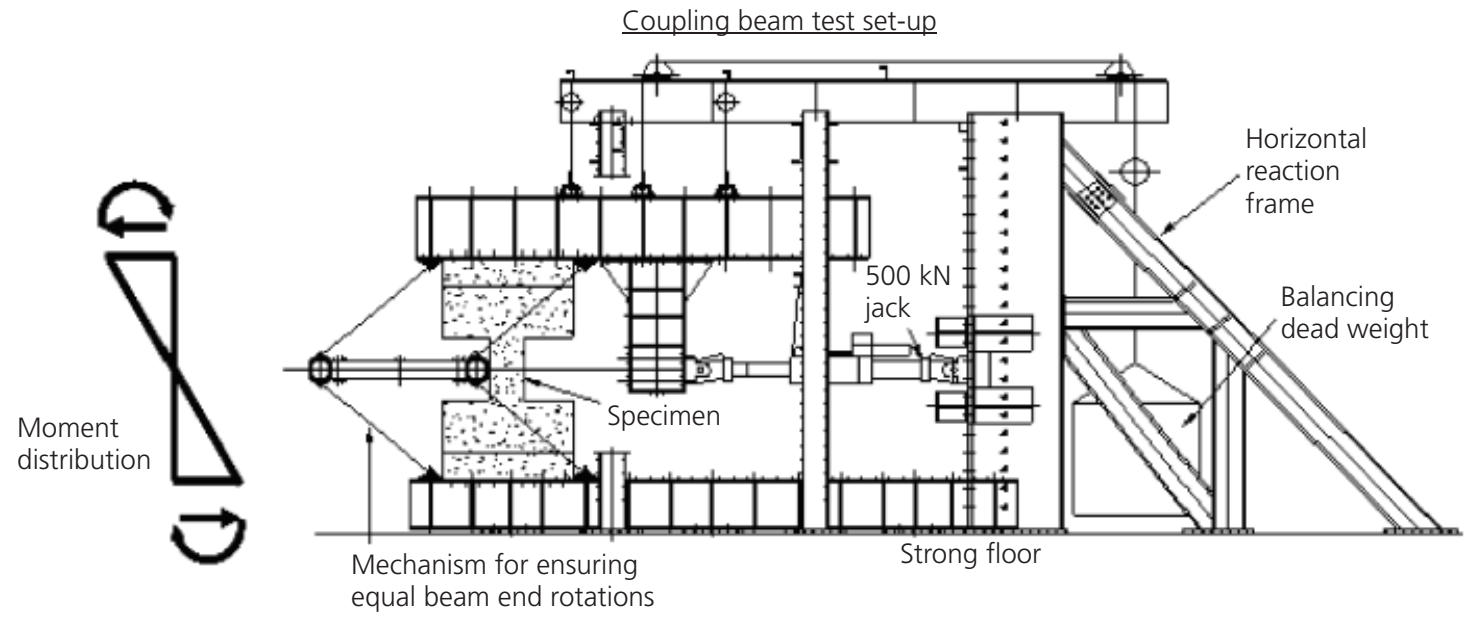

Figure 1. Test set-up 
the top end was attached to a structural steel beam that was moved horizontally during the loading process. Reversed cyclic loading was applied by a $500 \mathrm{kN}$ servo-controlled hydraulic actuator through a rigid arm to the top end of the specimen, with the line of action of the applied shear force passing through the beam. In this way, the coupling beam was loaded with a constant shear force along the span and a linearly varying bending moment with the point of inflection located at the mid-span, which simulated the situation in a real building.

\subsection{Description of test specimens}

Four specimens with the same dimensions (see Figure 2(a)) were fabricated and tested. The sizes of coupling beams were $450 \mathrm{~mm}$ deep by $120 \mathrm{~mm}$ wide with a clear span of $500 \mathrm{~mm}$ and a spanto-depth ratio of $1 \cdot 11$. The beam was connected to two RC panels (simulating part of the coupled shear walls) to properly model the beam-wall interactions. Two base beams were attached to the top and bottom ends of each $90^{\circ}$ rotated specimen in order to fix the specimen onto the loading frame through anchor-bolt connections. The reinforcement details, which were the same for all specimens, are shown in Figure 2(b). The top and bottom longitudinal reinforcements in the coupling beams were of four $12 \mathrm{~mm}$ diameter high-yield deformed reinforcement bars, and the side bars were of four $8 \mathrm{~mm}$ diameter mild steel round bars. The shear reinforcements in the coupling beams consisted of four $8 \mathrm{~mm}$ diameter hoops with $125 \mathrm{~mm}$ pitch. This shear reinforcement arrangement was selected to represent the shear-deficient coupling beams in old existing buildings.

The first specimen, DCB1, was used for control purposes with a plain RC arrangement. The other specimens, DCB2 to DCB4, were all strengthened with $3 \mathrm{~mm}$ thick, grade 50 steel plates. Owing to the limited load capacity of the load frame and the hydraulic actuator, the maximum applied shear load was $500 \mathrm{kN}$. The dimensions of the steel plates and the arrangements of anchor bolts of DCB2 to DCB4 are depicted in Figure 2(a). DCB2 was simply strengthened with a bolted steel plate, whereas DCB3 and DCB4 were strengthened with a bolted steel plate together with a buckling restraining device (see Figure 2(c)) mounted onto the beam span. Furthermore, for DCB4, two more anchor bolts were added at each end of the steel plate wall anchorages to restrain possible plate buckling between the bolt holes. By providing two steel members with equal angles section $(L 70 \mathrm{~mm} \times 70 \mathrm{~mm} \times 5 \mathrm{~mm}$ ) along the top and bottom edges of the steel plate, possible lateral buckling of the steel plate in the span of DCB3 and DCB4 was suppressed. To avoid adding extra strength to the steel plate, which would otherwise affect the comparison of test results among different specimens, the lateral stiffeners were connected to the steel plate by four bolt connections with slotted holes (see Figure 2(c)), which allowed the two lateral stiffeners to freely rotate and move in the longitudinal direction.

As all the steel plates were attached to coupling beams solely by bolt connections, the details of the connections could strongly influence the behaviour of the whole strengthening system. Ahmed et al. (1997, 2000) carried out experimental and theoretical studies of concrete floor beams with bolted side plates with particular emphasis on bolt slippage. They found that if the strength of bolts was low, bolts near the beam ends were fractured due to excessive interfacial slip between the plate and substrate. In this study, $20 \mathrm{~mm}$ diameter mild steel bolts were used to fix the external steel plate, whereas slightly larger clearance through $22 \mathrm{~mm}$ diameter holes were provided in the steel plates and concrete walls to allow for fabrication errors. To minimise any possible slippage among the various components at the connections, dynamic set washers developed by HILTI Corporation were used. The advantage of these washers is that bolt-slip can be minimised by injecting adhesive to fill all the gaps between the bolt shank and surrounding concrete (see Figure 2(a)). The specimens were instrumented with linear variable displacement transducers (LVDTs) to capture the deflection and curvature profiles, and strain gauges along the plates (for DCB2 to DCB4), longitudinal bars and stirrups to investigate the internal load distributions. The arrangements of the LVDTs and strain gauges are shown in Figure 3(a) and (b), respectively.

\subsection{Material properties}

Table 1 shows the concrete mix proportions used in the test. The mix used $10 \mathrm{~mm}$ maximum coarse aggregates and had a slump value of $60 \mathrm{~mm}$. Concrete compression tests were conducted on six cubes $150 \mathrm{~mm} \times 150 \mathrm{~mm} \times 150 \mathrm{~mm}$ and six cylinders $150 \mathrm{~mm} \times 150 \mathrm{~mm} \times 300 \mathrm{~mm}$ to obtain the average cube and cylinder compressive strengths $\left(f_{\mathrm{cu}}\right.$ and $\left.f_{\mathrm{c}}\right)$ on the days of testing, which were all on the 28th day after concrete casting. A design concrete cube strength of $30 \mathrm{MPa}$ was adopted in the tests to model the concrete strength of old structures. Two types of steel bars were used, high-yield deformed bars (T) and mild steel round bars $(\mathrm{R})$ with characteristic yield strength values of 460 and $250 \mathrm{MPa}$, respectively. Tensile tests of three $500 \mathrm{~mm}$ long samples of each type of steel bar were conducted to obtain their elastic moduli $(E)$ and tensile yield strengths $\left(f_{\mathrm{y}}\right)$. To determine the material properties of the steel plates, tensile tests of three $50 \mathrm{~mm} \times 400 \mathrm{~mm}$ samples of steel plate were conducted to obtain their stress-strain relationships. The material properties of the concrete, steel plate and reinforcements are given in Table 2.

\subsection{Testing procedure}

The specimens were tested under reversed cyclic loading to simulate earthquake or wind-applied forces. The loading process was divided into two phases; the first was load controlled and the second displacement controlled. The reversed cyclic loading was applied to each specimen up to $75 \%$ of the calculated theoretical ultimate shear capacity $\left(V_{\mathrm{u}}^{*}\right)$ (Table 3 ). The subsequent cycles were displacement controlled, in which the specimen was displaced to a nominal ductility factor $\left(\mu_{\mathrm{n}}=1\right)$ for one cycle, then to each successive nominal ductility factor for two cycles, as illustrated in Figure 4. The nominal ductility factor $\mu_{\mathrm{n}}=\theta / \theta_{\mathrm{yn}}$, where beam rotations $(\theta)$, defined as the differential displacement between the two beam ends $(\Delta)$ in the loading direction divided 
Structures and Buildings

Volume 164 Issue SB1
Plate-strengthened deep-reinforced

concrete coupling beams

Su and Cheng

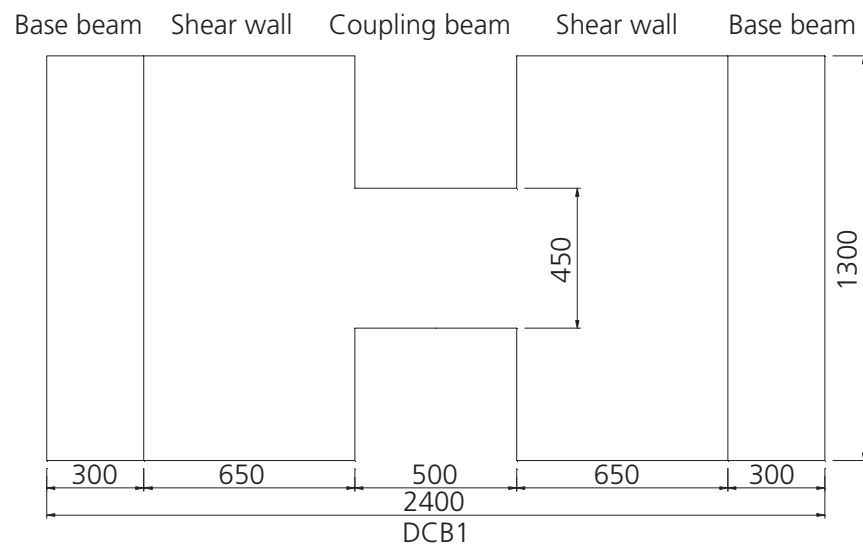

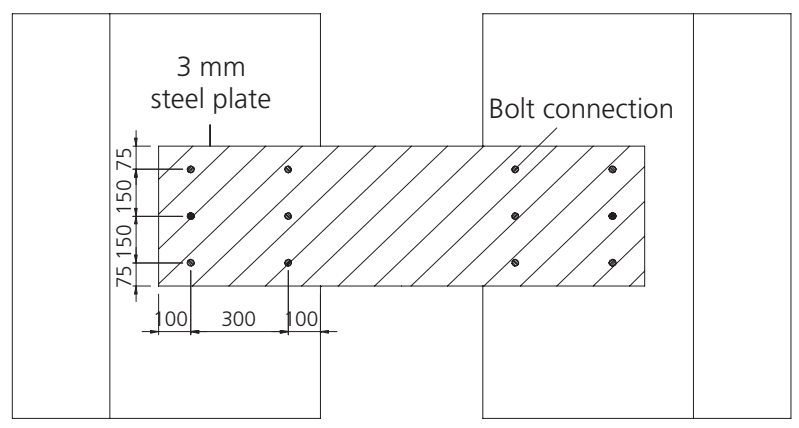

DCB2

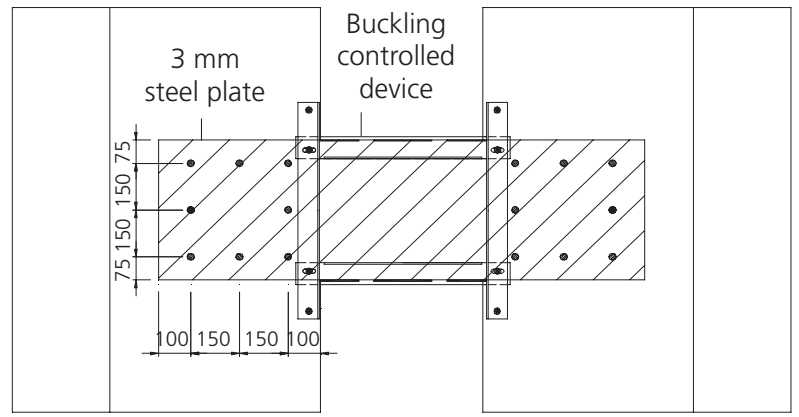

DCB4

DCB3

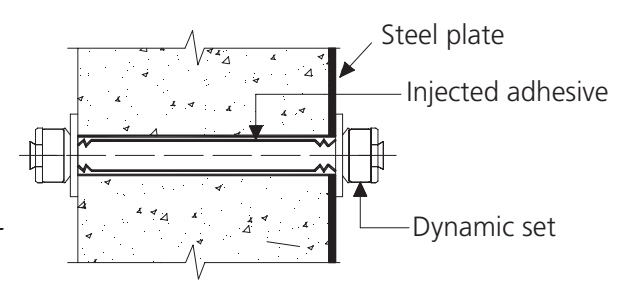

Bolt connection

(a)

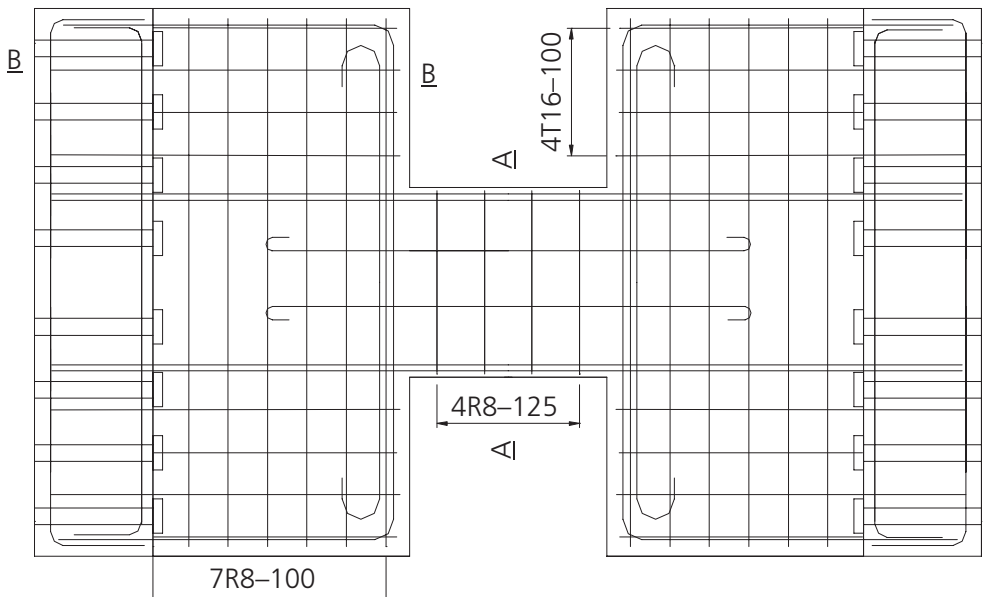

(b)

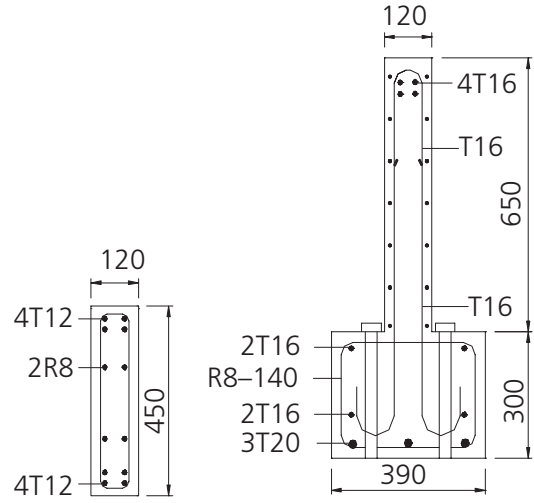

Section A-A $\underline{\text { Section B-B }}$

Figure 2. Details of test specimens: (a) configurations; (b) RC details 


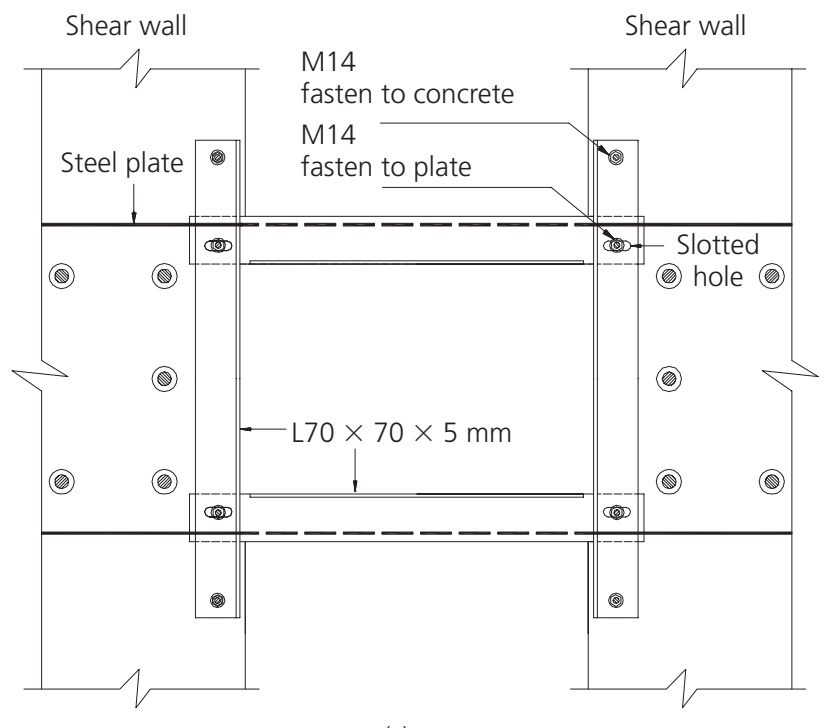

(c)

Figure 2. Details of test specimens: (c) buckling-controlled device

by the clear span $(l)$, were calculated using the displacements measured by LVDTs L3 and L4, as shown in Figure 3. The nominal yield rotation $\left(\theta_{\mathrm{yn}}\right)$ at $\mu_{\mathrm{n}}=1$ was obtained using the average of the $\theta$ values corresponding to the positive and negative loads at $0 \cdot 75 V_{\mathrm{u}}^{*}$ in the first cycle, following the $4 / 3$ rule (Park, 1988). The actual yield rotation $\left(\theta_{\mathrm{y}}\right)$ was later obtained in the same manner from the maximum measured shear $\left(V_{\max }\right)$. The test was terminated when the peak load reached in the first cycle of a nominal ductility level fell below the lesser of $0 \cdot 8 \mathrm{~V}_{\mathrm{u}}^{*}$ and $0 \cdot 8 \mathrm{~V}_{\max }$; at this point, the test specimen was considered to have failed.

\section{Results and discussion}

\subsection{Crack patterns and failure behaviour}

The experimental results for the specimens are summarised in Table 3. DCB4 achieved the highest shear load capacity $(346 \mathrm{kN}$; an average of the peak shear loads in the positive and negative cycles) as well as the highest chord rotation capacity (0.022 rad). In comparison with the control specimen DCB1, the strength and deformability of DCB4 were increased by 45 and $83 \%$, respectively. Although the failure mode of the four specimens was associated with shear failure, DCB3 and DCB4 failed in a less brittle manner due to the presence of the buckling restraining device.

For DCB1, diagonal cracks formed when the applied loads reached approximately $\pm 148 \mathrm{kN}$. After cracking, the lateral stiffness was drastically reduced, even though the specimen could still sustain higher shear loads. For the specimens strengthened by a bolted steel plate, diagonal cracks initiated at a slightly later stage when the applied load reached 172, 163 and $179 \mathrm{kN}$, respectively, for DCB2 to DCB4. After cracking, the lateral stiffness was only moderately reduced. The presence of a steel plate helped bridge the cracks and transferred shear force across the diagonal cracks.

Figure 5 shows the crack patterns of the reinforced concrete beams of the specimens after the tests. Diagonal crack patterns appeared on all the specimens, showing typical shear failure. DCB2 was found to have extensive concrete spalling as it underwent more load cycles than specimen DCB1. The steel plates of DCB3 and DCB4 were restrained laterally, so concrete spalling was suppressed in the post-peak range, resulting in slightly better deformability of the reinforced concrete. A more detailed description of the shear load resistance of concrete is given in Section 3.6.

\subsection{Load-rotation curves}

Figure 6 shows the load-rotation hysteresis loops of all the specimens. The load-rotation curve of the control specimen DCB1 exhibited substantial pinching after it reached the peak load. Such pinching is associated with rapid stiffness degradation and less energy dissipation in the post-peak regime. For platestrengthened specimens, in particular for DCB4 with more bolts added in the anchor region, the pinching effect was less severe and the energy dissipation in each hysteresis loop was much higher than that of the control specimen.

For DCB1, shear links started to yield when the load reached approximately $230 \mathrm{kN}$ (see Table 3). Soon after yielding, no more shear force could be resisted and the specimen had reached its peak capacity (also at $230 \mathrm{kN}$ ). The results demonstrated that insufficient shear reinforcement is the primary reason for failure of the control specimen, which agrees with the anticipated design failure mode. For DCB2, yielding of shear links happened at around $328 \mathrm{kN}$ and the average of peak load was $344 \mathrm{kN}$. The results also demonstrate a strong correlation between yielding of shear reinforcement and failure of DCB2. For DCB3, yielding of shear links and peak load also occurred at almost the same load of about $330 \mathrm{kN}$. Yielding of the shear link could accelerate the widening of the cracks. The presence of high tensile strains in the diagonal compressive struts could lead to eventual crushing failure of the concrete in the specimens. For DCB4, which had more bolts, whereas yielding of shear links occurred at $315 \mathrm{kN}$, the load-carrying capacity could still be increased by about $10 \%$ to 330 and $346 \mathrm{kN}$. Furthermore, as demonstrated in Figure 7, the chord rotation was increased from 0.0076 rad (link yielding) to $0.0123 \mathrm{rad}$ (peak load). Such ductile behaviour might be associated with the minor confinement effect provided by the steel plate pressed against the side face of the concrete beam, thereby preventing spalled concrete pieces from moving from their original positions and causing further deterioration of the concrete core. Although the same buckling restraining device was added to DCB3 and DCB4, the performance of DCB3 was not as good as that of DCB4 as a smaller number of bolts was used in the anchor regions.

The load-rotation results reveal that the behaviour and perform- 


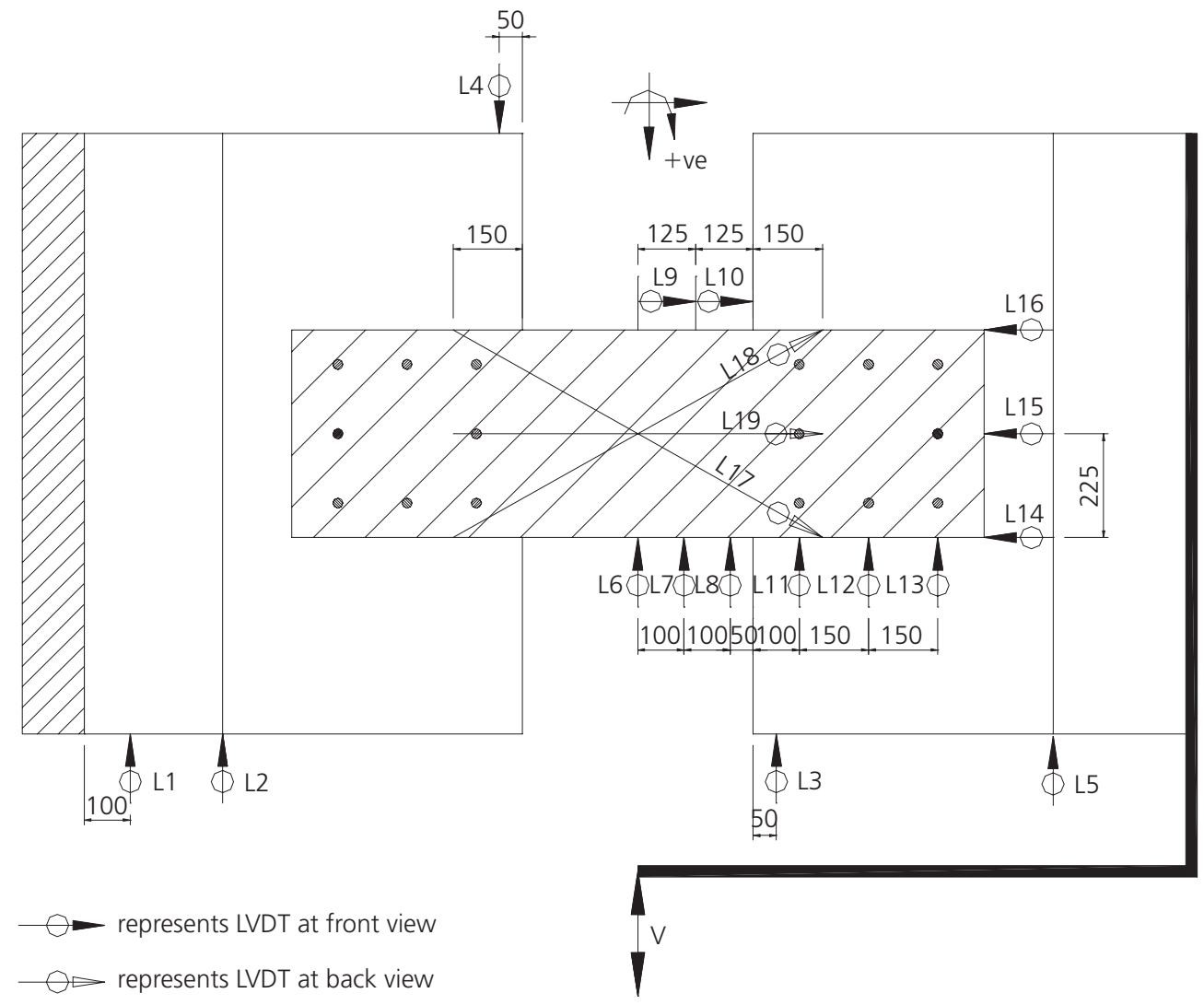

All dimensions in $\mathrm{mm}$

(a)
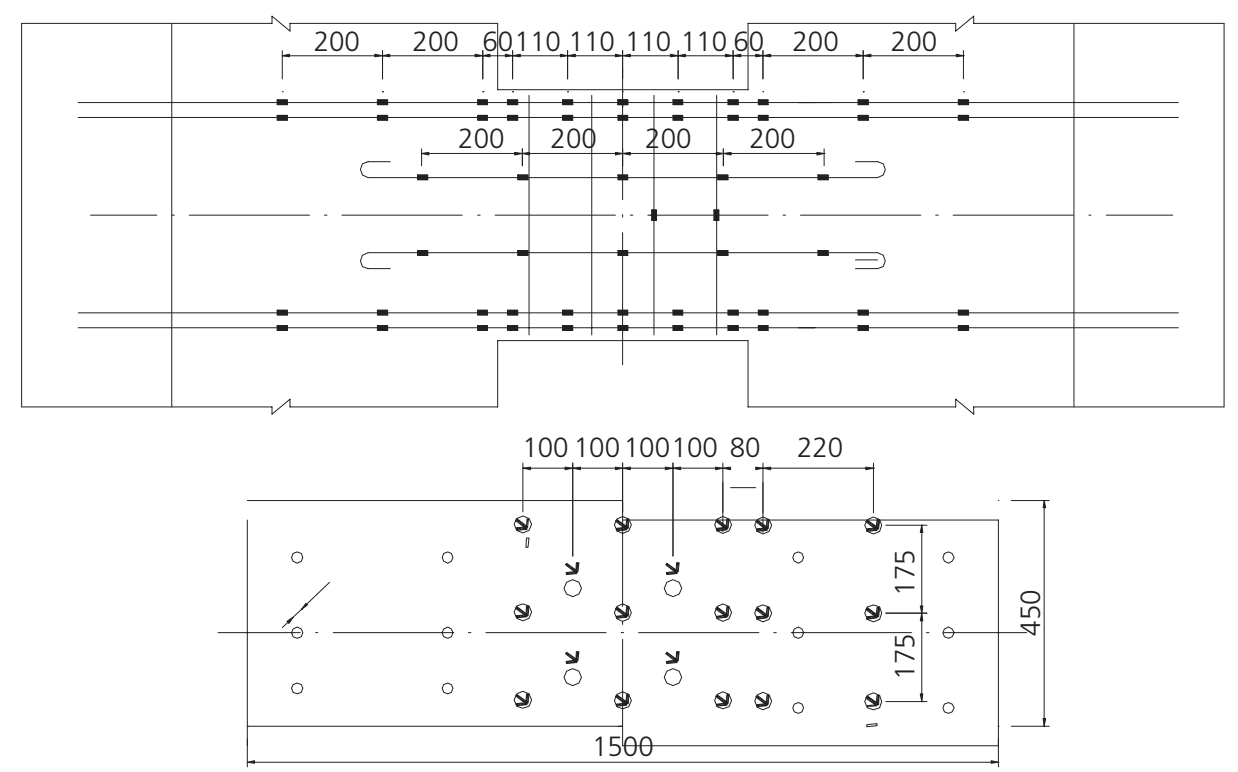

(2) represents rosette strain gauge

- represents strain gauge

All dimensions in $\mathrm{mm}$

(b)

Figure 3. Instrumentation: (a) LVDT arrangement; (b) strain gauge arrangement 


\begin{tabular}{lcccccc}
\hline $\begin{array}{l}\text { Water: } \\
\mathrm{kg} / \mathrm{m}^{3}\end{array}$ & $\begin{array}{c}\text { Cement: } \mathrm{kg} / \mathrm{m}^{3} \\
\text { ratio }\end{array}$ & $\begin{array}{c}\text { Water/cement } \\
\mathrm{kg} / \mathrm{m}^{3}\end{array}$ & $\begin{array}{c}\text { Fine aggregate: } \\
\mathrm{kg} / \mathrm{m}^{3}\end{array}$ & $\begin{array}{c}\text { Coarse aggregate: } \\
\mathrm{g} / \mathrm{m}^{3}\end{array}$ & $\begin{array}{c}\text { Superplasticiser: } \\
\text { aggregate: } \mathrm{mm}\end{array}$ & $\begin{array}{c}\text { Maximum } \\
\mathrm{mm}\end{array}$ \\
\hline 200 & 279 & 0.68 & 1025 & 838 & 0 & 10
\end{tabular}

Table 1. Concrete mix proportions

Concrete compressive strengths

\begin{tabular}{lcccc}
\hline Specimen & $f_{\text {cu }}:$ MPa & $\begin{array}{l}\text { Standard } \\
\text { deviation }\end{array}$ & $f_{\mathrm{c}}:$ MPa & $\begin{array}{c}\text { Standard } \\
\text { deviation }\end{array}$ \\
\hline DCB1 & 32.8 & 0.97 & 30.9 & 1.40 \\
DCB2 & 35.1 & 1.15 & 32.6 & 1.14 \\
DCB3 & 33.7 & 1.25 & 30.6 & 1.13 \\
DCB4 & 33.1 & 1.77 & 28.2 & 0.77 \\
\hline
\end{tabular}

Steel plate

\begin{tabular}{lcccc}
\hline Specimen & $f_{\text {yp }}:$ MPa & $\begin{array}{c}\text { Standard } \\
\text { deviation }\end{array}$ & $E:$ MPa & $\begin{array}{c}\text { Standard } \\
\text { deviation }\end{array}$ \\
\hline DCB2 & 359 & $12 \cdot 0$ & 203300 & 3600 \\
DCB3 & 362 & $1 \cdot 5$ & 206833 & 2480 \\
DCB4 & 354 & $13 \cdot 2$ & 205667 & 4190 \\
\hline
\end{tabular}

Reinforcement bars

\begin{tabular}{lcccc}
\hline Type & $f_{\mathrm{y}}: \mathrm{MPa}$ & $\begin{array}{c}\text { Standard } \\
\text { deviation }\end{array}$ & $E:$ MPa & $\begin{array}{l}\text { Standard } \\
\text { deviation }\end{array}$ \\
\hline T12 & 533 & $11 \cdot 4$ & 197900 & 3260 \\
T16 & 516 & $13 \cdot 2$ & 197867 & 3560 \\
T20 & 464 & $7 \cdot 3$ & 185533 & 2480 \\
R8 & 437 & $14 \cdot 6$ & 187400 & 2160
\end{tabular}

Table 2. Material properties

\begin{tabular}{|c|c|c|c|c|c|c|c|c|c|c|c|c|}
\hline Specimen & Brittleness, & $V_{u}^{*}: \mathrm{kN}$ & $\begin{array}{c}V_{\max } \\
\text { positive: } \\
\text { kN }\end{array}$ & $\begin{array}{c}V_{\max } \\
\text { negative: } \\
\text { kN }\end{array}$ & $\begin{array}{l}\text { Average } \\
V_{\max }: \mathrm{kN}\end{array}$ & $\begin{array}{c}V_{\max } \% \\
\text { increased }\end{array}$ & $\begin{array}{c}\text { Onset of } \\
\text { diagonal } \\
\text { cracks: } \\
\text { kN }\end{array}$ & $\begin{array}{c}\text { Yielding } \\
\text { of links: } \\
\text { kN }\end{array}$ & $\begin{array}{c}\text { Plate } \\
\text { buckling: } \\
\text { kN }\end{array}$ & $\theta_{\mathrm{y}}: \mathrm{rad}$ & $\begin{array}{c}\theta_{\max }: \\
\text { rad }\end{array}$ & $\begin{array}{c}K_{0}: \\
\mathrm{N} / \mathrm{mm}\end{array}$ \\
\hline DCB1 & serious & 230 & 260 & -201 & 238 & N/A & 148 & 230 & N/A & 0.0052 & 0.012 & 76 \\
\hline DCB2 & serous & N/A & 364 & -325 & 344 & $44 \%$ & 172 & 328 & 315 & 0.0085 & 0.019 & 67 \\
\hline DCB3 & slight & N/A & 330 & -300 & 315 & $32 \%$ & 163 & 330 & 330 & 0.0067 & 0.023 & 78 \\
\hline DCB4 & slight & N/A & 356 & -336 & 346 & $45 \%$ & 179 & 315 & 343 & 0.0072 & 0.022 & 80 \\
\hline
\end{tabular}

Table 3. Summary of experimental results 

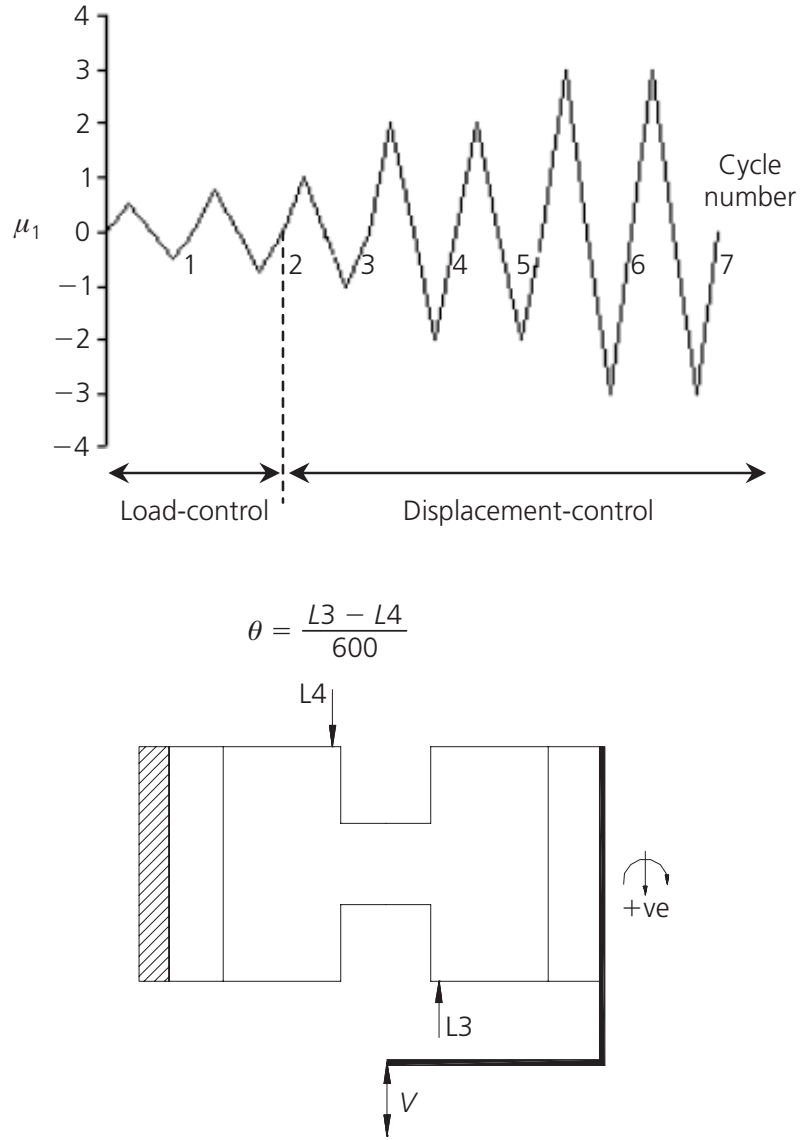

Figure 4. Loading history

ance of specimens under positive and negative load cycles were quite different, in particular for DCB1 and DCB2. Earthquake loads are, by their nature, a type of reversed cyclic loads. Strong asymmetric and highly varied responses in the positive and negative cycles for coupling beams are undesirable. It is therefore worthwhile to compare the positives and negatives of the backbone curves obtained from the load-rotation curves, together with their average (Figure 7). For DCB2 with buckling in the span, the mechanical properties of the steel plate at buckling in one loading direction were different from those in the opposite loading direction. Therefore, the hysteresis loops in the positive and negative loading directions were not symmetrical. Figure 7 shows that the variations of DCB3 and DCB4 in the positive and negative cycles were relatively small. This stable and repeatable response makes it suitable for seismic retrofitting.

For DCB2, unilateral local buckling of the steel plate began at compressive zones near the beam-wall joints when the load reached $315 \mathrm{kN}$. Plate buckling initiated at the beam span near the beam-wall joints and became more obvious with increasing shear load. The maximum shear load (the average of peak loads in positive and negative cycles) that could be resisted by the specimen was $344 \mathrm{kN}$. Figure 8 shows the buckling mode shapes recorded by the digital image correlation (DIC) technique devel- oped by La Vision Inc. Post-processing of the images was accomplished by the software package StrainMaster (La Vision, 2006). It was found that the buckling mode shape of DCB2 was symmetrical along the diagonal line. In the post-peak stage, plate buckling became serious, and the buckled plate formed a small pocket near the beam-wall joints holding the debris from spalling concrete. As a result of this, the plate could not deform back to its original flat position in the reversed load cycles. Furthermore, the debris jammed into the gap between the steel plate and concrete left some space for further spalling and deterioration of the concrete in subsequent load cycles.

For DCB3 and DCB4, although plate buckling was controlled in the span by lateral restraints, minor local buckling did occur at the anchor regions (as shown in Figure 8) when the load reached the average ultimate capacity of 330 and $346 \mathrm{kN}$. Apparently, local buckling controlled the strength of DCB3 and DCB4. If local buckling at the anchorage regions could be suppressed by adding more anchor bolts or lateral restraints, the strength and deformation of the composite beams might be further increased.

\subsection{Strength, energy dissipation and stiffness characteristics}

In order to compare the energy dissipation abilities of various specimens, the energy dissipated $\left(W_{\mathrm{d}}\right)$ in each half-cycle was evaluated. The values of $W_{\mathrm{d}}$ are equivalent to the area bounded by the load-displacement curves. Figure 9 shows the variations of $W_{\mathrm{d}}$ with the nominal ductility level of the first cycles in the positive and negative directions. It can be seen that the addition of the steel plate significantly enhanced the energy dissipation. In the early cycles, all the specimens were able to dissipate an increasing amount of energy, and after $\mu_{\mathrm{n}}=2$, the amount of energy dissipated decreased for all the specimens. DCB4 had the best energy dissipation ability as the imposed deformation increased.

Strength degradation in repeated cycles is determined by comparing the peak loads of each specimen at a nominal ductility level $\left(V_{\text {peak } 1}\right)$ and in repeated loading cycles $\left(V_{\text {peak2 }}\right)$. The retentions of load capacities in the first repeated cycles $\left(V_{\text {peak2 } 2} / V_{\text {peak } 1}\right)$ at each nominal ductility level are presented in Figure 10. The results demonstrate that the strength retention ability for plate-strengthened beams, in particular DCB3 and DCB4 with buckling-controlled device, was generally higher than for conventional RC coupling beams. This was mainly due to the fact that the steel plate in DCB3 and DCB4 dissipated energy through stable shear deformation. For DCB4, which had more bolts in the anchor region, the energy dissipation and strength retention ability were better than DCB3.

The secant stiffness $K_{0}$ was obtained by dividing the ultimate load by the yield displacement. As shown in Table 3, the addition of bolted steel plates did not increase the secant stiffness, because the increase in the yield displacements (or yield chord rotations) was higher than the increase in the strength. 
Structures and Buildings

Volume 164 Issue SB1
Plate-strengthened deep-reinforced concrete coupling beams

Su and Cheng

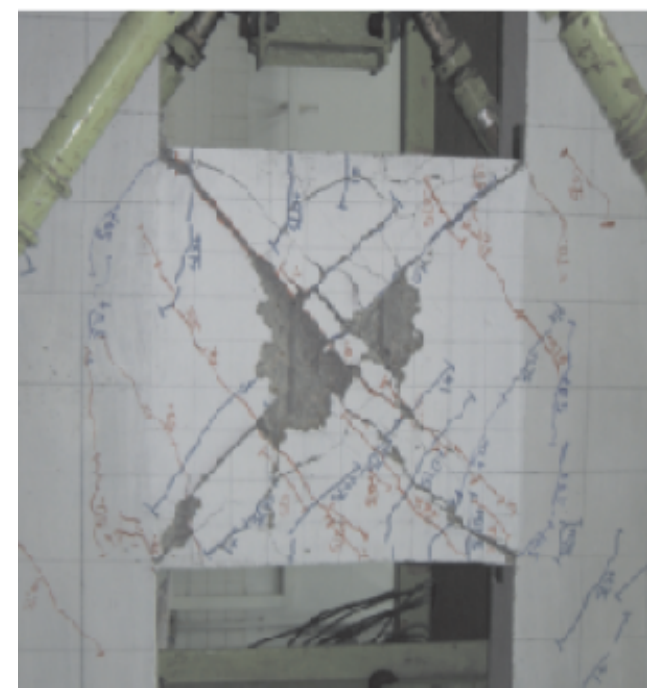

(a)

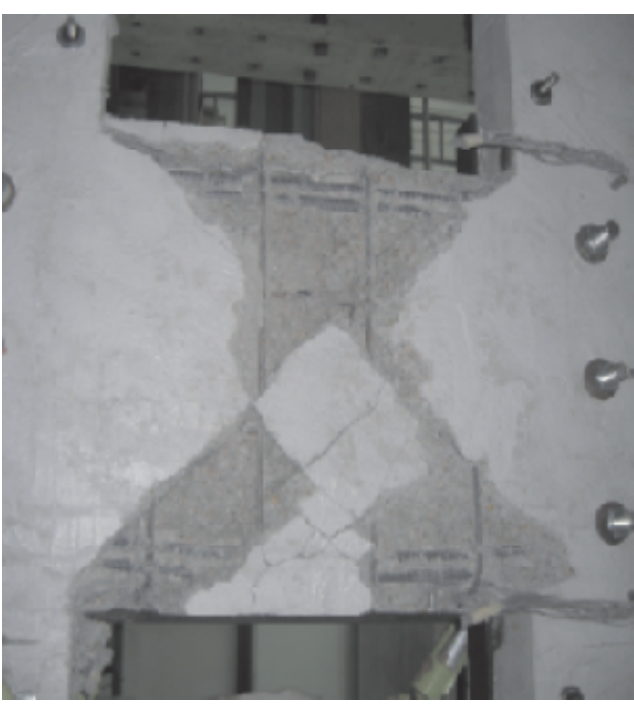

(c)

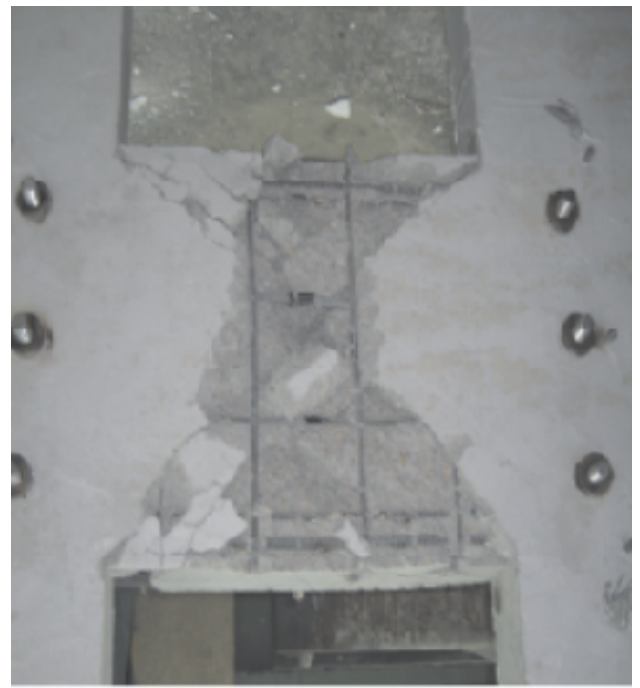

(b)

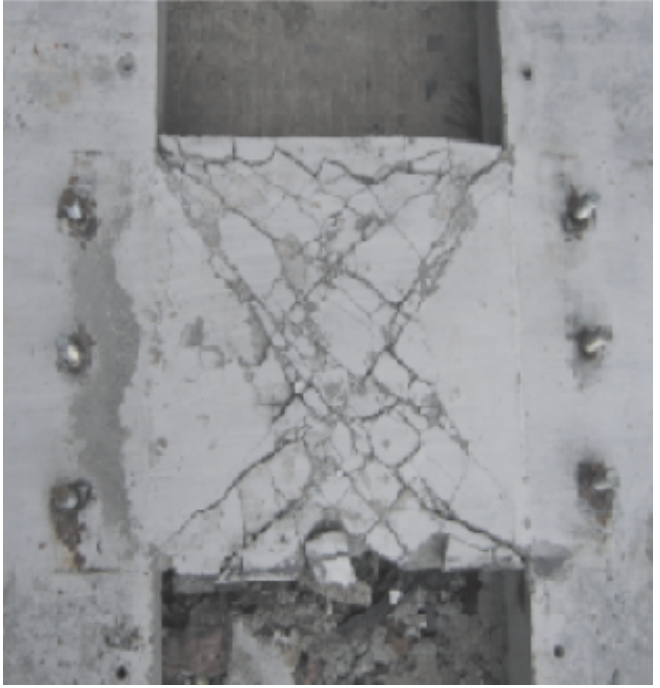

(d)

Figure 5. Concrete failure pattern after tests: (a) DCB1;

(b) DCB2; (c) DCB3; (d) DCB4

By comparing the test results of the four specimens it can be concluded that this new seismic retrofitting method can increase the energy dissipation ability and strength retention while avoiding the increase of their flexural stiffness.

\subsection{Axial extension in the reinforced concrete beams}

An LVDT (L19) was mounted at both ends of each concrete beam to measure the axial deformation of the specimens. Figure 11 summarises the results of the recorded axial deformations at the maximum and minimum loads in each of the cycles. It can be observed that all the concrete beams were extended after deformation. The expansion of the concrete spans is attributed to: (a) rotation of the diagonal strut in the concrete, causing the beam span to extend longitudinally, and $(b)$ because once the beam cracked, the crack faces could not be fully closed when the rotation returned to zero and hence permanent axial extension was left in the specimens after large rotations. For DCB1, after reaching the peak concrete strength at a chord rotation of 0.009 , the axial strength of the concrete struts degraded and hence axial deformations of the specimen were reduced in subsequent cycles. DCB2 to DCB4 had more axial deformation than DCB1 due to the contribution of steel plate. In the initial stage, the axial extensions of DCB2 to DCB4 were quite similar; this held until the chord rotation was higher than about $0.006 \mathrm{rad}$; from this point plate buckling began to occur. After plate buckling, the plate substantially lost compressive strength and axial stiffness. Its original compressive force was shared with the concrete component. Axial deformation of the steel plate was controlled 


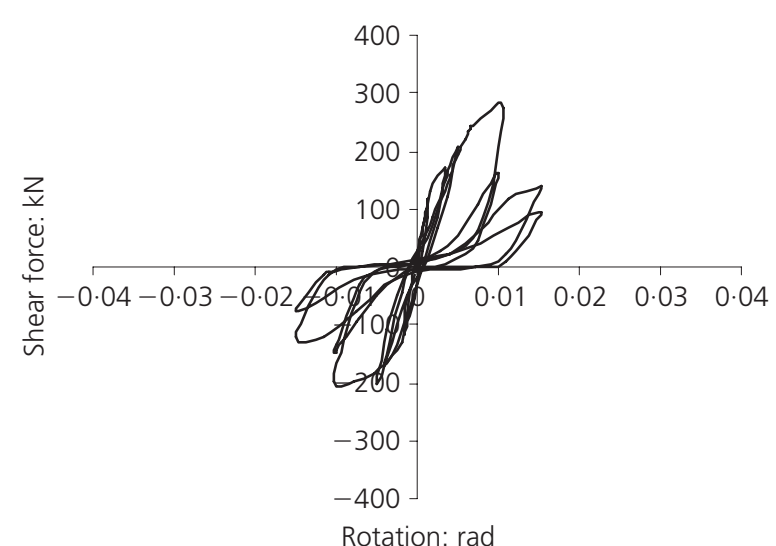

(a)

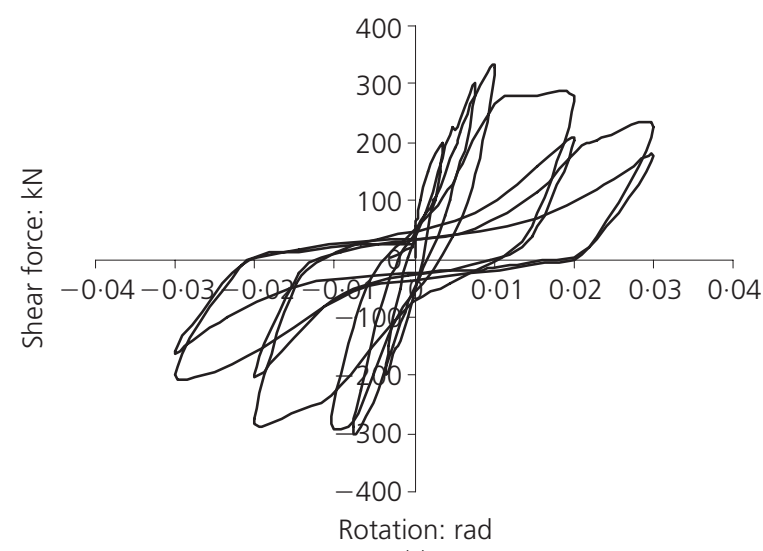

(c)

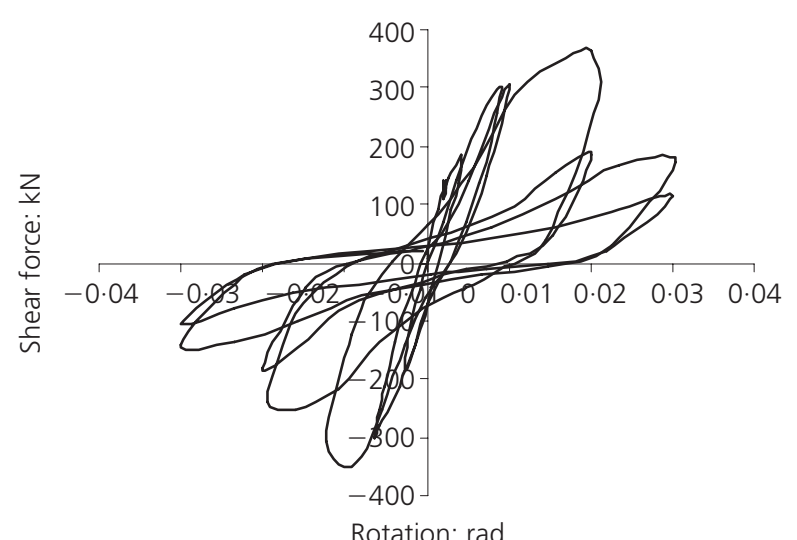

(b)

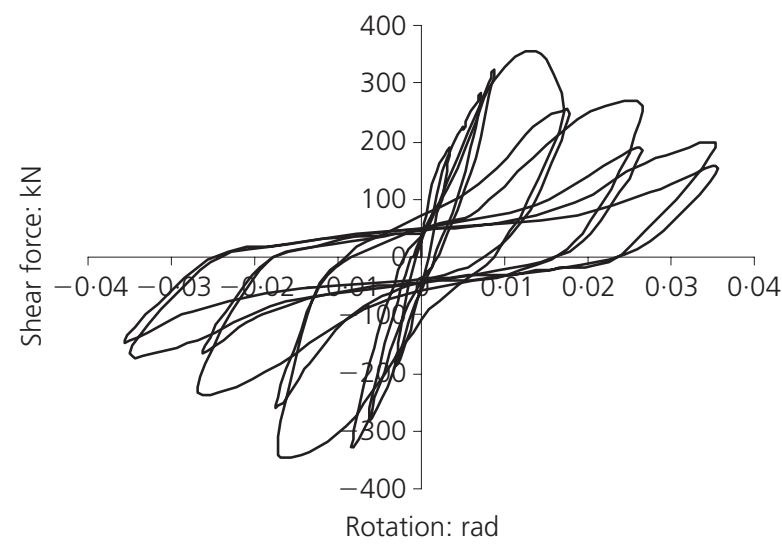

(d)

Figure 6. Load-rotation curve: (a) DCB1; (b) DCB2; (c) DCB3; (d) DCB4

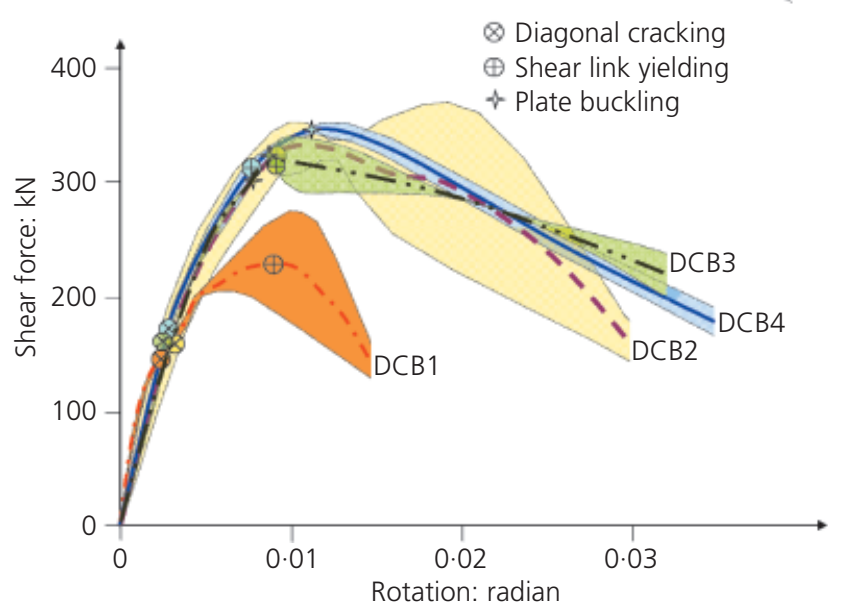

Figure 7. Envelopes of the load-rotation curves by the stiffer RC part until the concrete reached its peak strength at around $0.01 \mathrm{rad}$. After this, the strengths of the concrete strut and the steel plate both degraded and hence the axial deformation of the specimen also decreased gradually in subsequent cycles. The value of axial deformation of DCB4 was higher than the others. This was because buckling of the steel plate of DCB4 occurred in a later stage at a chord rotation of $0.011 \mathrm{rad}$, while tensile yielding of the plate occurred at a chord rotation of approximately $0.007 \mathrm{rad}$. The inelastic extension of the steel plate in reversed cycles caused DCB4 to elongate more than the others.

\subsection{Force distribution in the steel plates}

The shear and axial strains of the steel plates were obtained from the rosette strain gauges attached on the plate surfaces. By assuming a linear strain-stress relationship, the internal forces at each section could be calculated accordingly. Figure 12(a) shows the variations of the internal shear force at mid-span of the steel plate. The results reveal that the steel plates can take up more 


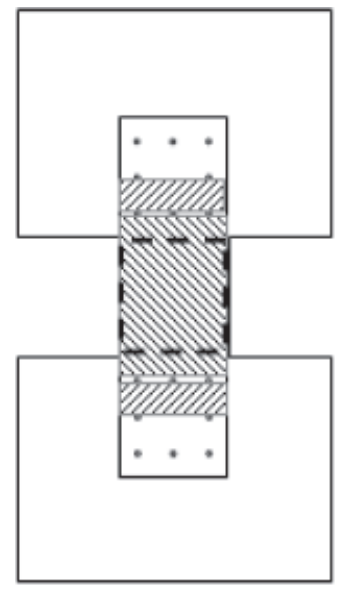

Local buckling regions

DCB2

DCB3

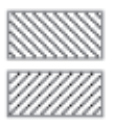

Region monitored by

DIC I- -

(a)

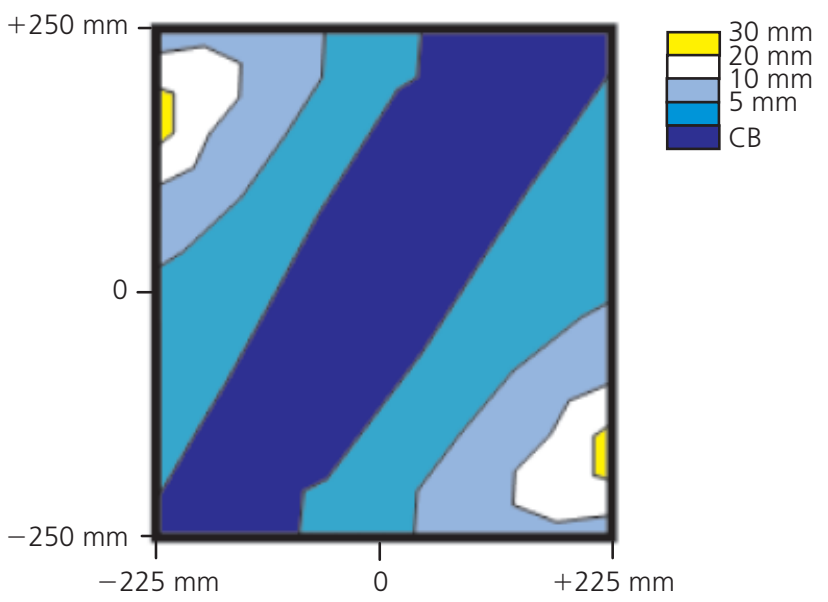

(b)

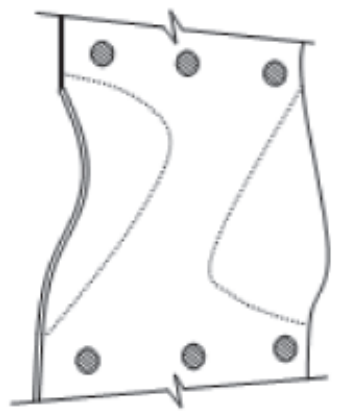

(c)

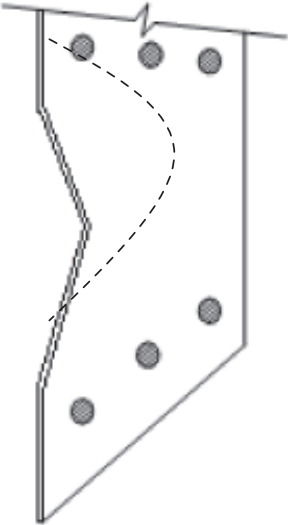

(d)

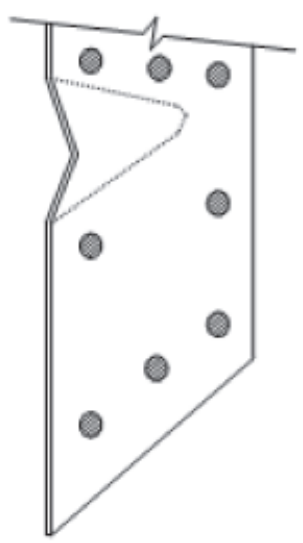

(e)

Figure 8. Buckling deformation: (a) locations of local plate buckling; (b) contour map of DCB2 by DIC; (c) sketch of DCB2; (d) sketch of DCB3; (e) sketch of DCB4

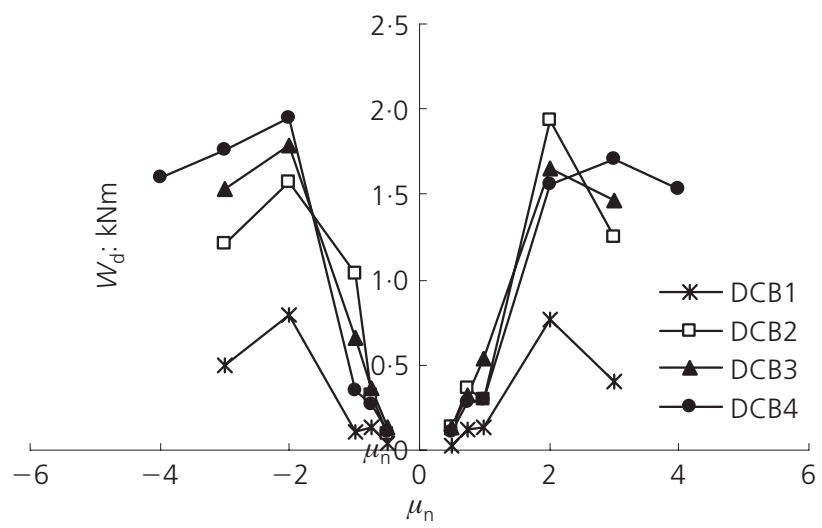

Figure 9. Energy dissipated at nominal ductility in the first cycles

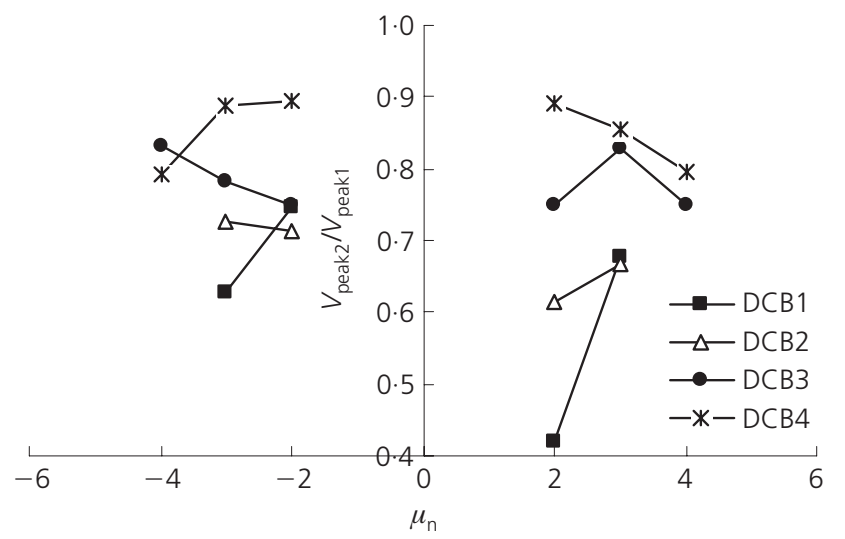

Figure 10. Strength retentions in the repeated cycles 


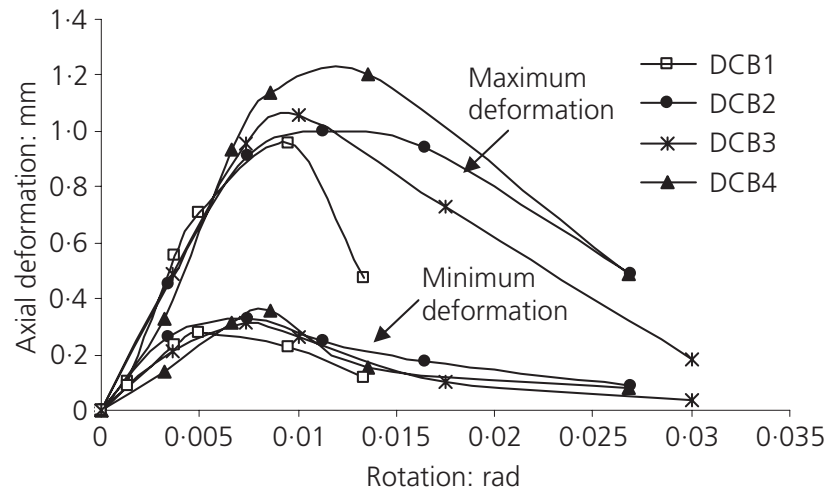

Figure 11. Axial deformation of RC part

shear force as the chord rotation increases. After plate buckling occurred in the beam span of DCB2, the surface of strains became uneven and hence the calculated force became inaccurate. The inaccurate parts of the curves in Figure 12 are dotted. The hysteretic behaviour of shear force resisted by the steel plate in DCB2 was different from that of DCB3 and DCB4. In DCB2, due to plate buckling, energy dissipation in the steel plate was mainly through the diagonal plastic extension of the plate. As a result, a relatively high compressive axial force was generated in the concrete counterpart to balance the tensile force. In DCB3 and DCB4, on the other hand, lateral restraining device was provided for the steel plate to control buckling; the energy dissipated in the plate was in the form of in-plane shear deformation, which was relatively stable and effective for transferring shear (Figure 12(a)). Moreover, much more energy could be dissipated with the increase of chord rotations for DCB4 with more bolts in the anchor regions.

Figure 12(b) presents the variation of axial load with the chord rotation. For DCB3 and DCB4, the axial plate force was always positive, which means that the plate was in tension throughout the test. The extension of the steel plate, as mentioned in Section 3.4, was caused by the extension of the RC part during beam rotation. For DCB2, owing to local plate buckling in the beam span when the chord rotations exceeded $\pm 0.0075 \mathrm{rad}$, the surface strains measured on the plate surface became inaccurate. The inaccurate part of the calculated axial forces is shown as a dotted line in Figure 12(b).

After the first ductility cycle, a negative plate force was calculated, implying that the plate was contracted longitudinally. These results violated the fact of extension of the steel plate.

\subsection{Shear force in reinforced concrete}

By subtracting the total beam shears (Figure 6) from the steel plate shears (Figure 12(a)), the shear forces resisted by the RC beams were calculated. Figure 13 shows the shear force envelopes of the RC beams. Note that the deformability of the RC beams with bolted steel plates was slightly improved and the rotations corresponding to the peak shear loads were increased from 0.009 rad (for DCB1) to 0.011 and 0.013 rad for DCB2 to DCB4, respectively. The small increase in $\mathrm{RC}$ beam rotation may be due to the additional local joint rotation (of the order of 0.003 to $0.005 \mathrm{rad}$ ) induced by the applied moment from the plate anchors. More details of the lateral and rotational movements of the bolt anchors are presented in the next section.

The rotations at which the shear links started to yield are marked on Figure 13. After yielding of the shear links for DCB1, DCB2 and DCB3, the RC beams attained their peak loads. Hence, the strength of those concrete beams was controlled by the strength and number of shear links provided. By comparing DCB3 and DCB4, the RC beam of DCB4 achieved a much better load retention after yielding of the shear links. This means that the provision of sufficient strength at the anchor regions is important to enable the effectiveness of the buckling restraining device. As mentioned in Section 3.1, the laterally-restrained steel plate might help to suppress further concrete spalling in the post-peak range and hence improve the deformability of RC beams.

\subsection{Movements of anchor bolt groups}

Using the arrangement of LVDTs (L11-L16), as shown in Figure 3 , the average translational and rotational movements at the centre of anchor bolt groups were captured. The transverse and longitudinal movements of the anchor bolt groups are shown in Figure 14(a) and (b), respectively. The figures show that the transverse movements were of the order of $\pm 1 \mathrm{~mm}$. The longitudinal movements of DCB2 (with a maximum of $-1 \mathrm{~mm}$ ) and DCB3 (with a maximum of $-1.05 \mathrm{~mm}$ ) were much larger than that of DCB4 (with a maximum of $-0.6 \mathrm{~mm}$ ). This implies that stretching of the steel plate and hence the longitudinal movements of the bolt group of DCB2 and DCB3 were much higher. This is reasonable, as lateral buckling caused the steel plate to be subjected to a net axial tension, and to resist the tensile force, the bolt anchors were moved towards the centre of the beam.

The rotational movements of the bolt groups were also evaluated using the records from the LVDTs. The rotation determined from the LVDT readings in the longitudinal direction is called the 'longitudinal rotation', whereas that determined from the LVDT records in the transverse direction is termed 'transverse rotation'. Figures 15(a) and (b) present, respectively, the transverse and longitudinal rotations of the bolt groups. The results show that the rotations recorded in the transverse and longitudinal directions generally agree. For DCB3, as an insufficient number of bolts were provided in the anchor regions, the bolt group rotation kept increasing as the beam chord rotation increased and might exceed the corresponding elastic limit. Apart from DCB3, the maximum rotations of the bolt groups for DCB2 and DCB4 were of the order of 0.003 to $0.005 \mathrm{rad}$. Above the maximum bolt group rotation, only the chord rotation increased. This demonstrated that the bolt groups were strong enough and were able to maintain elastic conditions, while the beams underwent inelastic deformation. Furthermore, the small bolt group rotations indicate 

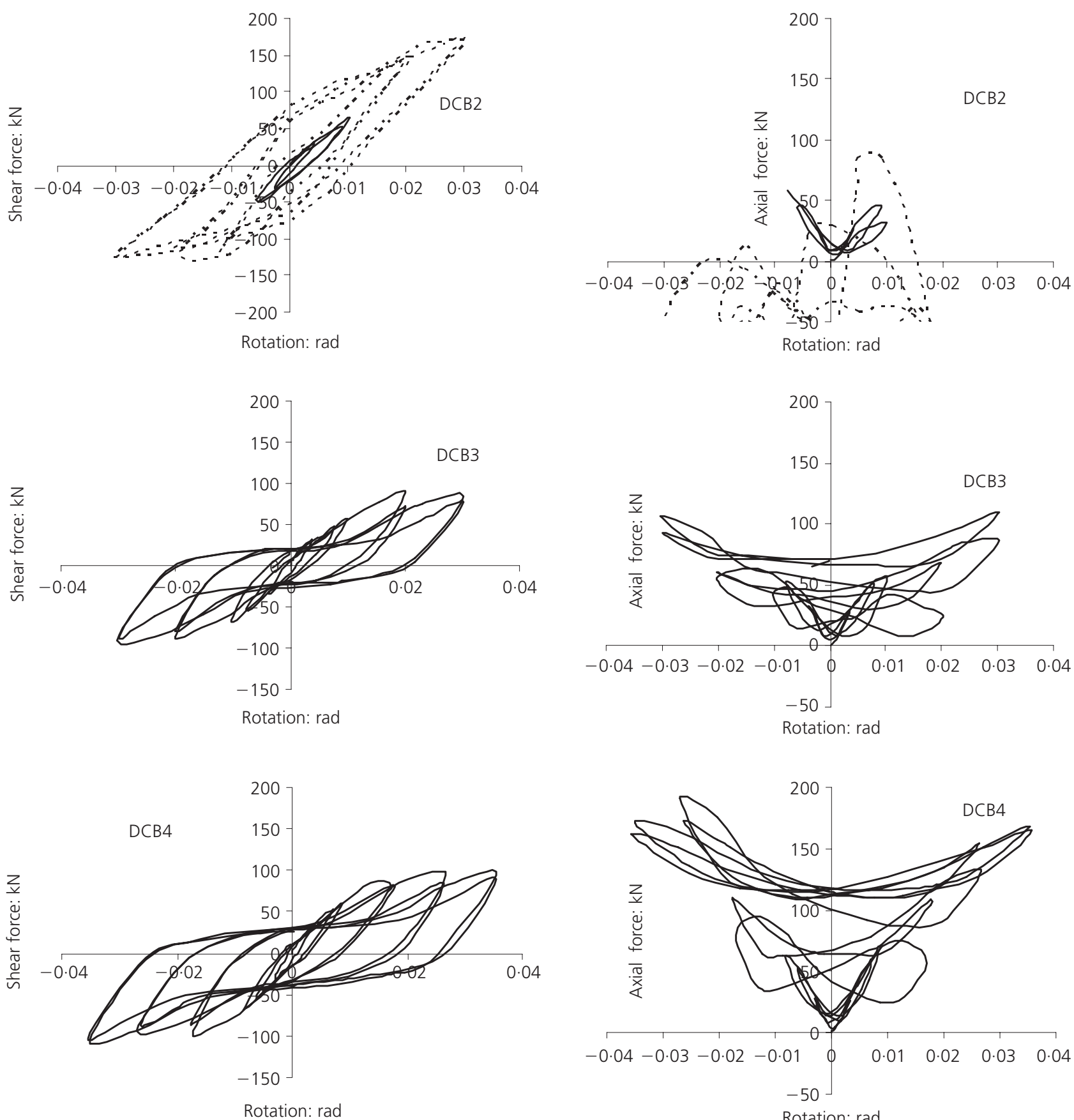

(a)

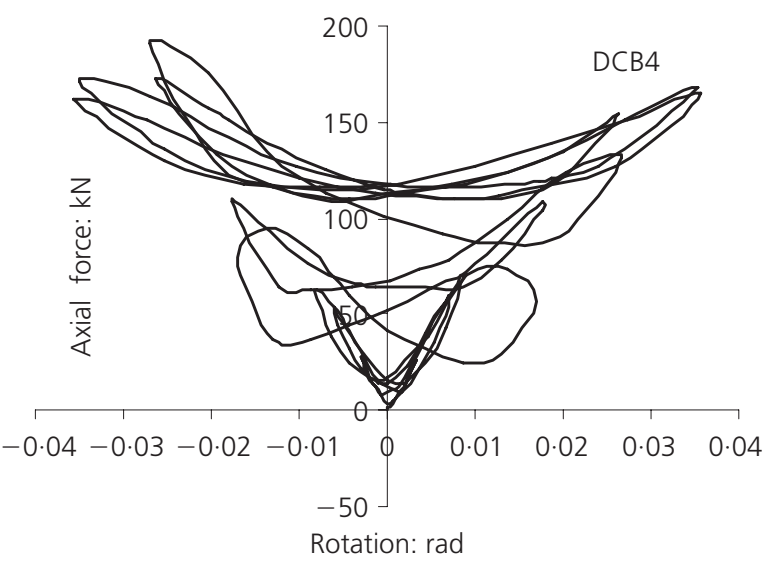

(b)

Figure 12. Steel plate internal forces: (a) shear component;

(b) axial component

that the stiffness of the bolt groups was sufficiently high. This further confirms the effectiveness of dynamic set washers, which reduced slipping between the concrete, the bolts and the steel plates.

\section{Conclusions}

An experimental study of steel plate-strengthened deep RC coupling beams was conducted. The main findings of this study are summarised in the following list. 


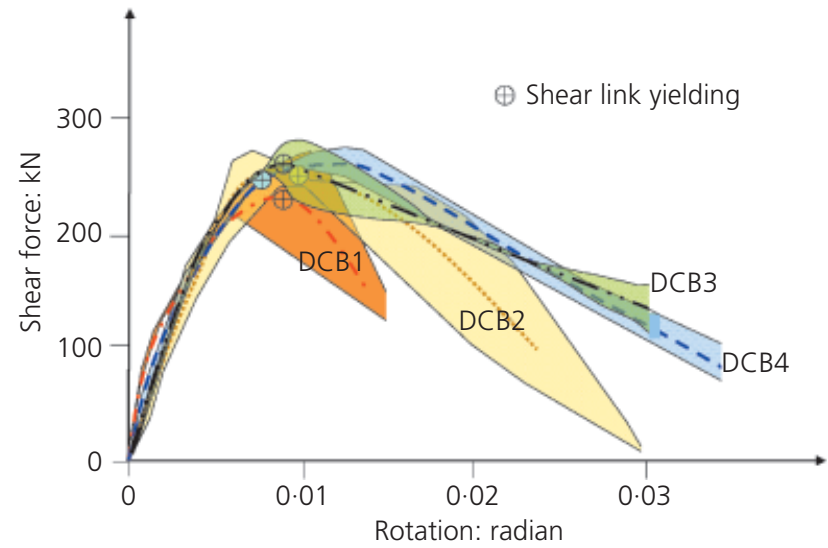

Figure 13. Concrete shear force envelopes

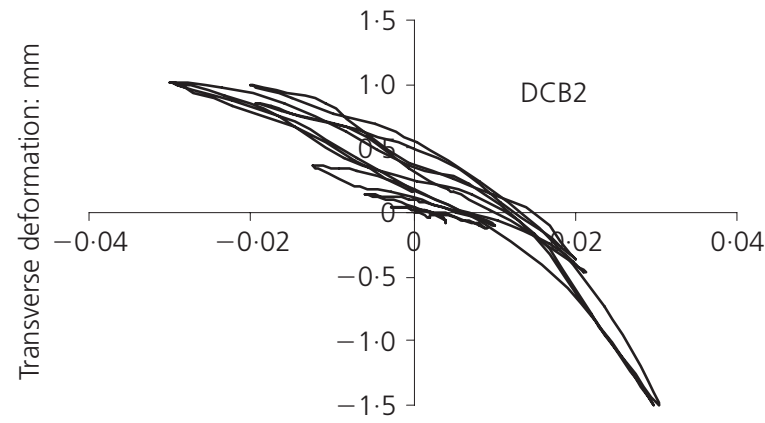

Rotation: rad

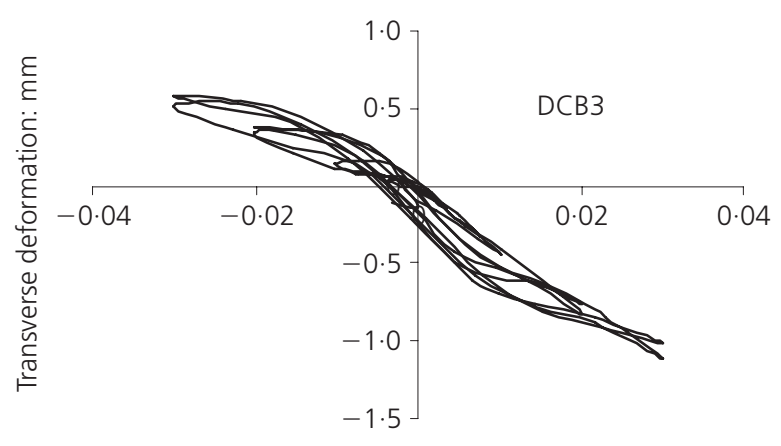

Rotation: rad

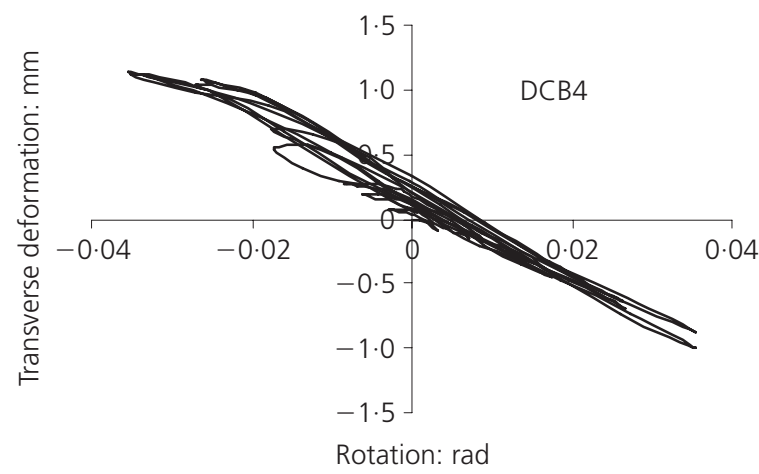

(a)

Figure 14. Translational movements of bolt group in (a) transverse direction, (b) longitudinal direction (a) This strengthening method effectively improves the shear capacity, energy dissipation ability and deformability of conventional RC deep coupling beams. Failure of the beam was changed to a less brittle manner.

(b) By comparing the structural performances of DCB2 with DCB3 and DCB4, a buckling-restraining device was found to be superior as more ductile failure pattern, less pinching, higher energy dissipation, more stable energy absorption (due to predominant shear deformation in the plate), higher loadretention capacity in the repeated cycles and a more symmetric response under reversed cyclic loads can be achieved while the stiffness was not increased. These desirable features make this method suitable for seismic retrofitting of deep coupling beams in high seismicity areas.
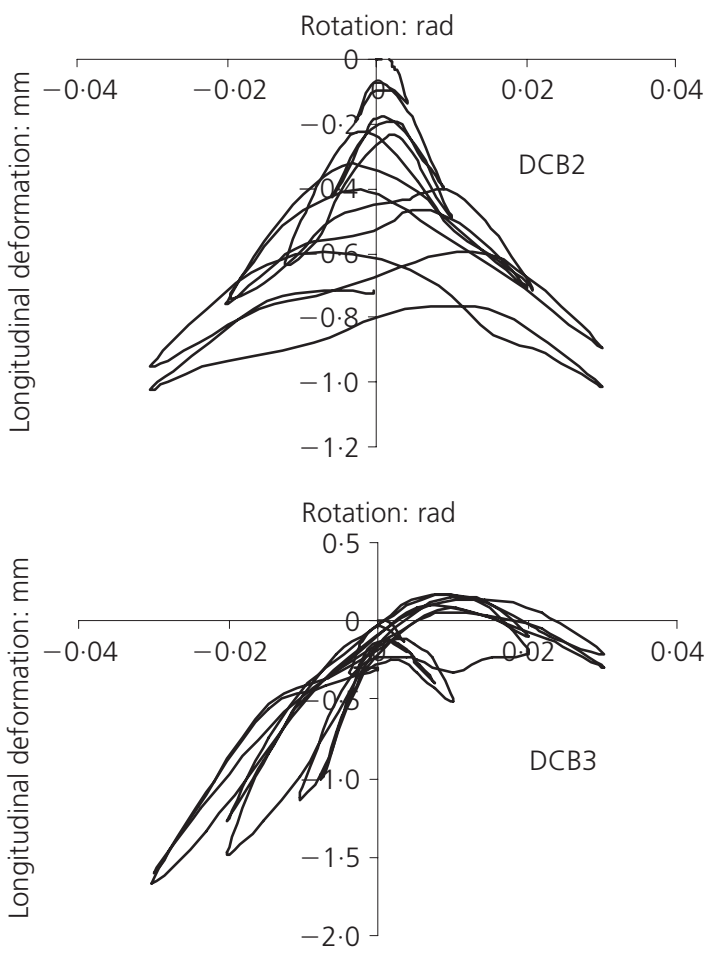

Rotation: rad

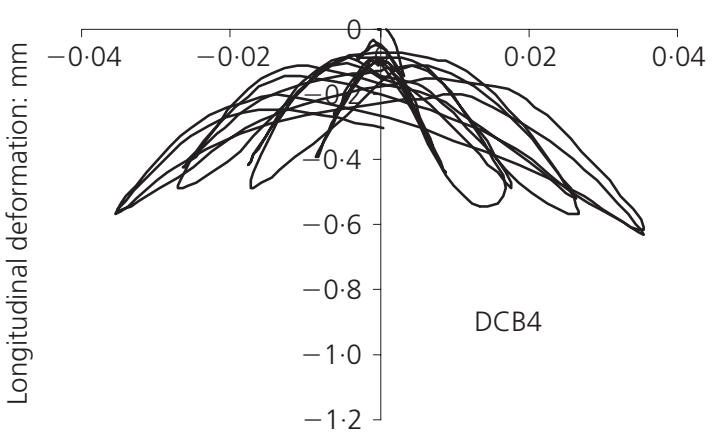

(b) 

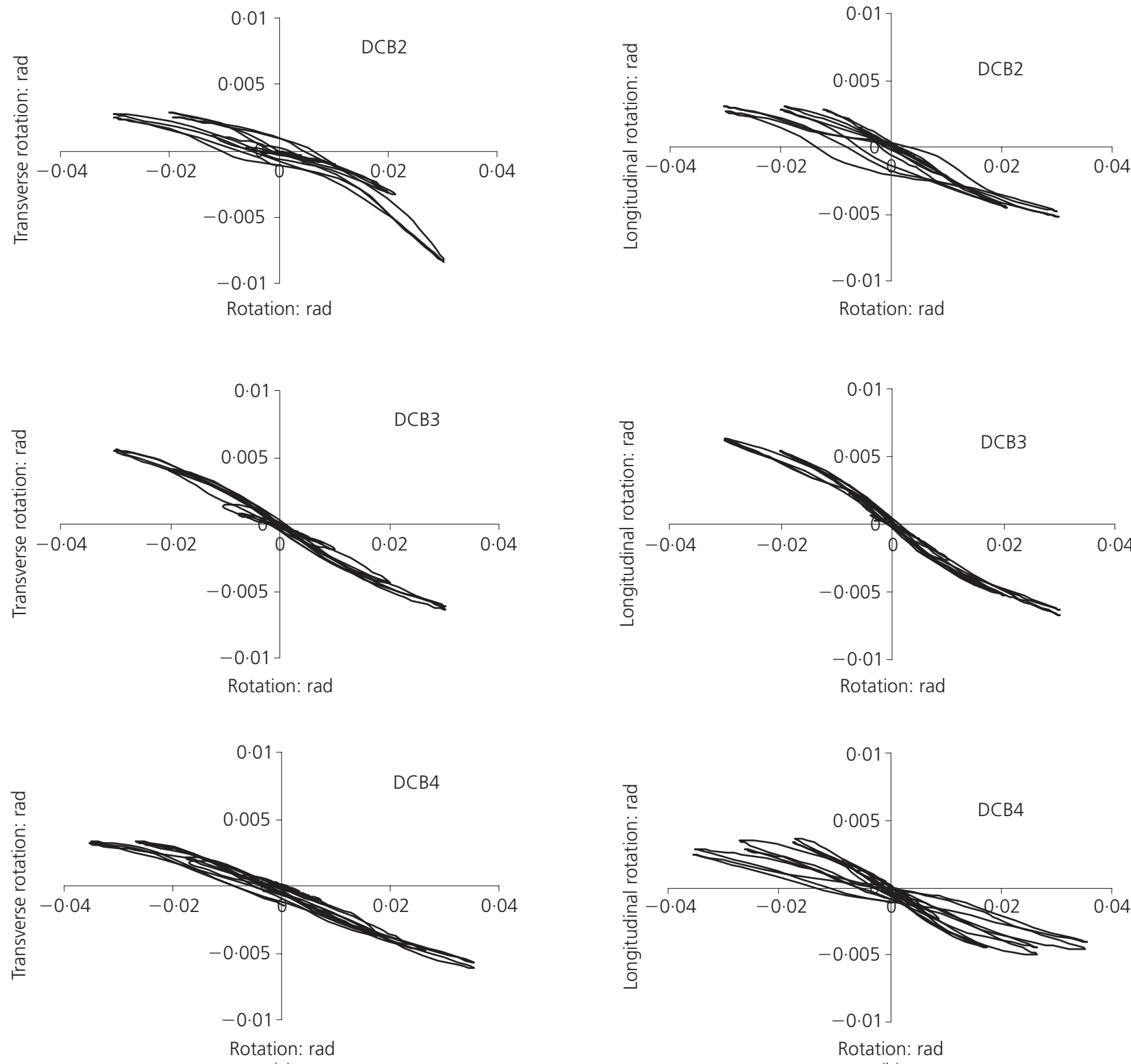

(a)

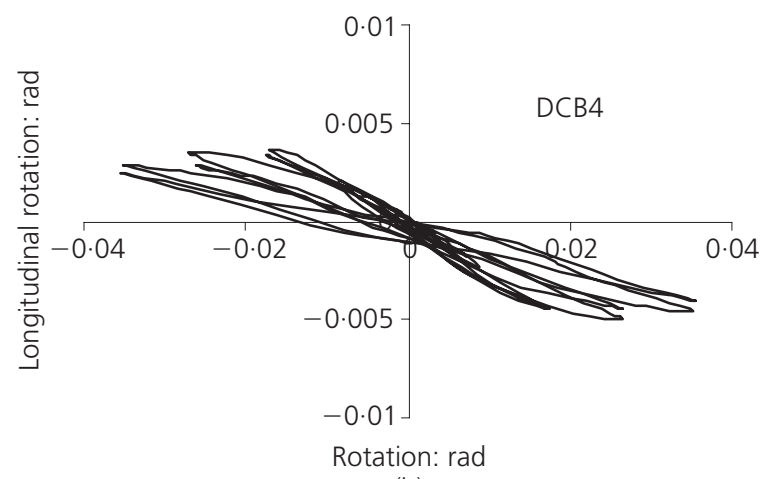

(b)

Figure 15. Rotations of bolt group: (a) transverse rotation; (b) longitudinal rotation

(c) By comparing the structural performances of DCB3 and DCB4, it was found that the specimen with an adequate number of bolts provided in the anchor region had better energy dissipation and strength retention abilities.

(d) RC beams strengthened with steel plates have slightly higher deformability. This phenomenon is partially attributed to the addition of local joint rotation induced by the applied moment from the plate anchors.

(e) After yielding of links, the RC beam with a laterally restrained steel plate had slightly better inelastic deformation.
This is probably due to the fact that the steel plate suppressed further spalling and damage to the concrete in the post-peak regime.

$(f)$ If plate buckling at the anchor regions can be suppressed (by adding more bolts, reducing the bolt pitch or providing thicker steel plate at anchorage), the strengthened coupling beams can have higher deformability, better energy dissipation ability and more ductile performance.

(g) By using thin and lightweight steel plate, this method is easy to install on-site. Furthermore, as there is no need for any 
surface polish process and drilling of bolt holes along the beam span, the labour cost can be reduced and the construction time can be shortened.

\section{Acknowledgements}

The work described herein has been fully supported by the Research Grants Council of Hong Kong SAR (Project No. HKU7168/06E). Anchor bolts were generously supplied by HILTI Corporation and are gratefully acknowledged.

\section{REFERENCES}

Ahmed M, Oehlers DJ and Bradford MA (2000) Retrofitting reinforced concrete beams by bolting steel plates to their sides, Part 1: Behavior and experiments. Structural Engineering and Mechanics 10(3): 211-226.

Ahmed M, Oehlers DJ, Nguyen NT and Bradford MA (1997) Reinforced concrete beams with steel plates bolted to their sides. Proceedings of the 5th International Conference on Structural Failure, Durability and Retrofitting, Singapore, 27-28 November, 362-369.

Harries KA, Cook WD and Mitchell D (1996) Seismic retrofit of reinforced concrete coupling beams using steel plates. $A C I$ Special Publication 160 6(1): 93-114.

Harries KA, Mitchell D, Cook WD and Redwood RG (1993) Seismic response of steel beams coupling concrete walls. Journal of Structural Engineering, ASCE 119(12): 36113629.

Kwan AKH and Zhao ZZ (2002a) Cyclic behavior of deep reinforced concrete coupling beams. Proceedings of the Institution of Civil Engineers, Structures and Buildings 152(3): 283-293.
Kwan AKH and Zhao ZZ (2002b) Testing of coupling beams with equal end rotation maintained and local joint deformation allowed. Proceedings of the Institution of Civil Engineers, Structures and Buildings 152(1): 67-78.

Lam WY, Su RKL and Pam HJ (2005) Experimental study on embedded steel plate composite coupling beams. Journal of Structural Engineering, ASCE 131(8): 1294-1302.

La Vision (2006) User's Manual of Davis 7.2-StrainMaster3D. La Vision, Michigan, USA.

Park R (1988) Ductility evaluation from laboratory and analytical testing. Proceedings of the 9th World Conference on Earthquake Engineering, Tokyo-Kyoto, Japan, 2-9 August, 605-616.

Paulay T (1971a) Simulated seismic loading of spandrel beams. Journal of the Structural Division, ASCE 97(ST9): 24072419.

Paulay T (1971b) Coupling beams of reinforced concrete shear walls, Journal of the Structural Division, ASCE 97(ST3): $843-862$.

Paulay T and Binney JR (1974) Diagonally reinforced coupling beams of shear walls. ACI Special Publication SP-42(26): 579-598.

Su RKL and Zhu Y (2005) Experimental and numerical studies of external steel plates strengthened reinforcement concrete coupling beams. Engineering Structures 27(10): 1537-1550.

Teng JG, Chen JF and Lee YC (1999) Concrete-filled steel tubes as coupling beams for RC shear walls. Proceedings of the 2nd International Conference on Advanced Steel Structures, Hong Kong, 391-399.

Teng JG, Chen JF, Smith ST and Lam L (2002) FRP: Strengthened $R C$ Structures. Wiley, Chichester.

\section{WHAT DO YOU THINK?}

To discuss this paper, please email up to 500 words to the editor at journals@ice.org.uk. Your contribution will be forwarded to the author(s) for a reply and, if considered appropriate by the editorial panel, will be published as a discussion in a future issue of the journal.

Proceedings journals rely entirely on contributions sent in by civil engineering professionals, academics and students. Papers should be $2000-5000$ words long (briefing papers should be 1000-2000 words long), with adequate illustrations and references. You can submit your paper online via www.icevirtuallibrary.com/content/journals, where you will also find detailed author guidelines. 